\title{
Poluição atmosférica proveniente da queima de combustíveis derivados do petróleo em veículos automotores
}

\author{
Fernanda Caroline Drumm', Ademir Eloi Gerhardt'², Gabriel D'avila Fernandes ${ }^{3}$, \\ Patricia Chagas ${ }^{4}$, Mariana Scheffer Sucolotti ${ }^{5}$, Pedro Daniel da Cunha Kemerich ${ }^{6}$

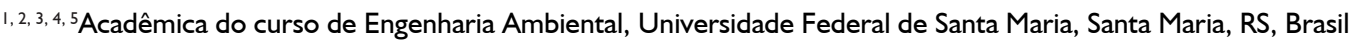 \\ 'Universidade Federal de Santa Maria, Santa Maria, RS, Brasil
}

Resumo

A poluição gerada nos grandes centros urbanos tem origem, principalmente, pela queima de combustíveis fósseis, basicamente gasolina e diesel, que são substâncias de origem mineral formadas pelos compostos de carbono, provenientes da decomposição de materiais orgânicos, a qual perdura milhões de anos. Logo, são considerados recursos naturais não renováveis. A queima destes combustíveis acontece de forma incompleta quando utilizados em máquinas térmicas e veículos automotores, este processo resulta no lançamento de uma grande quantidade de monóxido e dióxido de carbono (gás carbônico) na atmosfera, fazendo destes grandes vilões no que se refere ao aquecimento global e efeito estufa. Vale salientar que estes combustíveis alimentam os setores industrial, elétrico e de transportes de grande parte das economias do mundo. Este trabalho tem como finalidade levantar aspectos ligados à poluição atmosférica decorrente da utilização de veículos automotores.

Palavras-chave: poluição atmosférica, combustíveis fósseis, veículos.

\begin{abstract}
The pollution generated in large urban centers follows mainly from burning fossil fuels, basically gasoline and diesel, which are mineral substances formed by carbon compounds from the decomposition of organic materials, what take millions of years. Therefore, they are considered non-renewable resources. The fuel burning occurs incompletely when employed in heat engines and automotive vehicles, and this process results in release of a large amount of carbon monoxide and carbon dioxide emissions, making these great villains regarding to global warming and the greenhouse effect. It is worth noting that these fuels feed the industrial, electrical and transport of most world economies. This work aims to raise issues related to air pollution from motor vehicles use.
\end{abstract}

Keywords: air pollution, fossil fuels, vehicles. 


\section{INTRODUÇÃO}

A poluição atmosférica urbana vem sendo um dos maiores problemas que assolam a sociedade, não só dos países industrializados, mas também daqueles em desenvolvimento. Com o aumento das emissões atmosféricas nas últimas décadas, são notáveis os impactos causados pela poluição atmosférica nas comunidades e no meio ambiente, que são afetados negativamente de modo constante pelos níveis elevados de poluição do ar, visto que a qualidade do ar é diretamente influenciada pela distribuição de emissões veiculares e industriais, bem como a intensidade das mesmas revela-se de crucial importância para estudo destas emissões (CETESB, 2011).

O Brasil está entre os países que sofreu um notável aumento na motorização individual, fato que implica na intensificação do tráfego de veículos nos grandes centros urbanos e nos congestionamentos cada vez mais frequentes. Além disso, o crescimento do número de veículos causa impactos negativos no meio ambiente, devido à poluição sonora e do ar (FILIZOLA, 2004).

Segundo Azuaga (2000) a poluição atmosférica pode ser definida como a presença de substâncias nocivas, na atmosfera, em quantidade suficiente para afetar sua composição ou equilíbrio, prejudicando o meio ambiente e as mais variadas formas de vida. Este tipo de poluição causa sérios impactos não só na vida humana, como também na vida animal e vegetal, além da deterioração de bens culturais de lazer e da inutilização ou depreciação dos recursos naturais.

Para Teixeira et al (2008) as fontes veiculares têm tido uma participação acentuada na degradação da qualidade do ar atmosférico, especialmente nos grandes centros urbanos. Dentre as questões habituais da realidade destes grandes centros estão os congestionamentos de grandes extensões em horários de pico, a redução da velocidade média do trânsito nos corredores de tráfego e o maior gasto de combustível.

Teixeira et al (2008) afirma que as emissões causadas por veículos automotores carregam uma grande variedade de substâncias tóxicas, as quais quando em contato com o sistema respiratório, podem ter os mais diversos efeitos negativos sobre a saúde. Essas emissões, devido ao processo de combustão e queima incompleta do combustível, são compostas de gases como: óxidos de carbono (CO e CO2), óxidos de nitrogênio (NOx), hidrocarbonetos ( $\mathrm{HC}$ ), dentre os quais estão alguns considerados cancerígenos, óxidos de enxofre ( $\mathrm{SOx}$ ), partículas inaláveis (MP10), entre outras substâncias.

Segundo estimativa da CETESB (2004), os veículos automotores são responsáveis pelas emissões de $83,2 \%$ de CO; $81,4 \%$ de HC; $96,3 \%$ de NOx; 38,9\% de MP10 e 53\% de SOx na Região Metropolitana de São Paulo, concluindo que estes produzem mais poluição atmosférica que qualquer outra atividade humana e, com isso, se tornam grandes agentes agressores do meio ambiente e da saúde pública.

Azuaga (2000) afirma que entre os danos ao ambiente e à saúde humana, causados pela emissão desses poluentes, destacam-se a acidificação de rios e florestas, o ataque aos materiais, o aumento de problemas respiratórios e circulatórios na população, bem como a perda de bem estar da população, além do efeito estufa e do aquecimento global. Nota-se que os danos provenientes da poluição atmosférica não se restringem somente às áreas onde ocorreu a emissão, pois através da dispersão por meio das correntes de ar, as partículas e gases ultrapassam fronteiras regionais e nacionais.

Com base no exposto, o objetivo do presente trabalho é demonstrar os impactos na esfera ambiental e social causado pela emissão de gases provenientes da queima incompleta de derivados de petróleo por meio de veículos automotores, entendendo-se por "veículo automotor" todo o veículo provido de motor, de categoria leve ou pesado.

\section{REFERENCIAL TEÓRICO}

\section{I PolUição ATMOSFÉRICA}

Carvalho (2009) afirma que, dentre as diversas formas de degradação ambiental, a poluição do ar atmosférico é uma das que mais prejuízos trazem à civilização, afetando a saúde humana, os ecossistemas e o patrimônio histórico cultural, assim como o clima.

Considera-se poluente atmosférico qualquer substância presente no ar e que pela sua concentração possa torná-lo impróprio, nocivo ou ofensivo á saúde, inconveniente ao bem estar público, danoso às matérias, á fauna e à flora ou, ainda, prejudicial à segurança, ao uso da propriedade e atividades normais da comunidade ( Lisboa e Kawano 2007) 
A qualidade do ar de uma região é influenciada diretamente pelos níveis de poluição atmosférica, os quais estão vinculados a um complexo sistema de fontes emissoras estacionárias (indústrias, queima de lixo, emissões naturais, entre outras) e móveis (veículos automotores, aviões, trens). A magnitude do lançamento dessas emissões, seu transporte e diluição na atmosfera, determinam o estado atual da qualidade do ar atmosférico (Cunha 2002)

Loureiro (2005) classifica os poluentes atmosféricos em dois grandes grupos: poluentes primários e poluentes secundários Os poluentes primários são emitidos diretamente pelas fontes emissoras, como exemplo: o monóxido de carbono, o dióxido de enxofre, NOx, entre outros. Estes poluentes podem, na baixa atmosfera, sofrer transformações e reações fotoquímicas dando origem a poluentes denominados secundários. Dado que a formação de poluentes secundários, tais como o ozônio, necessita de certo tempo e ocorre à medida que as massas de ar se deslocam, é normal que concentrações elevadas destes poluentes atinjam áreas mais afastadas das fontes de emissão que os poluentes primários.

Segundo Tundo e Zecchini (2007), os poluentes primários, depois de emitidos para a atmosfera, estão submetidos a processos complexos de transporte, mistura e transformação química, que dão origem a uma distribuição variável das suas concentrações na atmosfera, tanto no espaço como no tempo. Basicamente, as distribuições das concentrações de poluentes na atmosfera dependem das condições de emissão e das condições meteorológicas, podendo alguns poluentes ser transportados a grandes distâncias antes de atingirem o nível do solo.

\subsection{PRINCIPAIS POLUENTES ATMOSFÉRICOS E FONTES}

\subsection{IMonóxido de Carbono}

É um gás incolor e inodoro, venenoso e produto de combustões incompletas em veículos automotores. Por isso, a poluição por monóxido de carbono é encontrada, em altos níveis de concentração, em áreas de intensa circulação de veículos nos centros urbanos (PCPV 2005).

O monóxido de carbono $(\mathrm{CO})$ é emitido diariamente em centenas de milhões de toneladas à atmosfera, sendo oriundos de processos naturais e antropogênicos. O monóxido de carbono é um poluente que apresenta grande toxicidade ao ser humano. E um produto intermediário resultante do processo de combustão em situações de baixa concentração de oxigênio (Guimarães, 2011).

\subsubsection{Material Particulado (MP)}

Sob a denominação de material particulado (MP), se encontra uma classe de poluentes constituídas de poeiras, fumaças e todo o tipo de material sólido e líquido que, devido ao pequeno tamanho, mantém-se suspenso na atmosfera. As fontes destes poluentes vão desde as incômodas "fuligens" emitidas pelos veículos até as fumaças expelidas pelas chaminés industriais, passando pela poeira que se deposita nas ruas e é movimentada pelos veículos. A legislação brasileira preocupava-se, até 1989, apenas com as Partículas Totais em Suspensão (PTS), ou seja, todos os tipos e tamanhos de materiais sólidos ou líquidos que ficam suspensos no ar, na forma de poeira, neblina, aerossol, fumaça ou fuligem com uma faixa de tamanho menor que $100 \mathrm{~mm}$, causando efeitos significativos em pessoas com doença pulmonar, asma e bronquite (PCPV, 2005).

Segundo Vesilind e Morgan (2011), pesquisas mostram que quanto menor o tamanho da partícula, maior o efeito sobre a saúde, ou seja, quanto mais fina a partícula, mais profunda ela penetra no aparelho respiratório. Desta forma, a partir de 1990, a legislação brasileira passou a também se preocupar com as Partículas Inaláveis (PI), menores que $10 \mathrm{~mm}$, originadas do processo de combustão industrial, de veículos automotores e do aerossol secundário (formado na atmosfera). Partículas minúsculas como as emitidas por veículos, principalmente os movidos a diesel, podem ser menores do que a espessura de um fio de cabelo.

\subsubsection{Dióxido de nitrogênio (NO2)}

Gás de cor marrom alaranjada, altamente tóxico ao ser humano, com odor forte e irritante. Pode levar a formação de acido nítrico, nitratos (o qual contribui para o aumento das partículas inaláveis na atmosfera) e compostos orgânicos tóxicos. Além disto, pode levar a formação da chuva ácida, causando danos à vegetação e à colheita (Vesilind e Morgan, 2011). 
Originado do processo de combustão envolvendo veículos automotores, processos industriais, usinas térmicas que utilizam óleo ou gás, esse gás é responsável também por causar sérios problemas de saúde (PCPV 2005).

\subsubsection{Ozônio (O3)}

O ozônio é um gás altamente reativo, incolor e inodoro nas concentrações ambientais, sendo o principal componente da névoa fotoquímica. É produzido quando os hidrocarbonetos e óxidos de nitrogênio reagem na atmosfera, ativados pela radiação solar. Embora tenha origem natural nas camadas superiores da atmosfera, onde exerce uma importante função ecológica, absorvendo as radiações ultravioletas do sol, pode ser nocivo nas camadas inferiores da atmosfera (Braga, 2005).

\subsection{IMPACTOS DA POLUIÇÃO ATMOSFÉRICA}

De acordo com Mota (2000), nem sempre é fácil estabelecer uma relação direta entre determinado poluente e os efeitos que o mesmo provoca no ambiente. A dispersão do poluente no ar, a distância que alcança sua concentração e o tempo de exposição ao mesmo são alguns fatores que influem nos impactos que podem causar. A poluição atmosférica pode resultar em impactos de alcances locais, regionais e globais.

\subsection{Impactos Locais}

Os impactos locais são aqueles verificados nas áreas próximas às fontes de poluição. Um dos principais efeitos da poluição atmosférica local é o dano que esses podem causar à saúde humana. Quando a concentração de poluentes do ar aumenta, sem que este seja adequadamente disperso pela ação da meteorologia, da topografia e de outros fatores, sérios problemas de saúde podem acabar ocorrendo (Moreira 2007). A tabela 1 mostra os principais poluentes emitidos por veículos que usam combustíveis fósseis e seus efeitos na saúde humana.

Tabela 1: Efeitos nocivos dos principais poluentes veiculares a saúde.

\begin{tabular}{cc}
\hline POLUENTES & EFEITOS NA SAÚDE \\
\hline $\mathrm{CO}$ & $\begin{array}{c}\text { Atua no sangue reduzindo sua } \\
\text { oxigenação, náuseas e intoxicação } \\
\text { NOx }\end{array}$ \\
$\mathrm{MP}$ & $\begin{array}{c}\text { Problemas respiratórios } \\
\text { Pode penetrar nas defesas dos } \\
\text { organismos, atingir os alvéolos } \\
\text { pulmonares e causar irritações asma, } \\
\text { bronquite e câncer nos pulmões }\end{array}$ \\
& $\begin{array}{c}\text { Irritação nos olhos, problemas } \\
\text { respiratórios e cardiovasculares }\end{array}$ \\
$\mathrm{Sox}$ & $\begin{array}{l}\text { Irritação nos olhos e problemas } \\
\text { respiratórios (reação inflamatória nas vias } \\
\text { aéreas }\end{array}$ \\
\hline
\end{tabular}

Fonte: Adaptado do IPEIA

Outro impacto local muito conhecido já nas grandes cidades é a diminuição da visibilidade, fenômeno facilmente observado (efeito Smog). A baixa visibilidade é extremamente prejudicial ao tráfego em geral e, em particular, ao tráfego aéreo. É, ainda, especialmente danosa em locais com pai- 
sagens turísticas. A redução da visibilidade pode ser causada por materiais particulados, por neblinas, nevoeiros, vapores que absorvem e dispersam luz (Moreira 2007).

O efeito smog é formado quando há a condensação de vapor d'água, porém, em associação com a poeira, fumaça e outros poluentes, o que dá um aspecto acinzentado ao ar. É muito comum a ocorrência desse fenômeno nas grandes cidades e metrópoles, sobretudo nos dias frios de inverno, quando ocorrem associados à presença de uma inversão térmica. A inalação do smog produz uma inflamação respiratória que pode persistir por até 18 horas, provocando tosse, dificuldade em respirar e intensificando asma, alergias e problemas cardíacos (Miranda e Baptista, 2008).

\subsubsection{Impactos Regionais ou Continentais}

Os impactos regionais são aqueles observados a distâncias maiores das fontes, Mota (2000) cita que um dos principais impactos regionais é a chuva ácida. Devido às correntes aéreas e regimes pluviais, as nuvens ácidas (formadas pelos gases $\mathrm{NOx} \mathrm{e} \mathrm{SO}_{2}$ ) podem deslocar-se por muitos quilômetros de seu ponto de origem, levando seus efeitos deletérios a regiões onde estes gases não são normalmente observados.

Ribeiro (2009) afirma que a acidificação das chuvas veicula como um dos mais graves problemas ambientais atualmente em diversas regiões, sobretudo, nos arredores de aglomerados industriais e dos grandes centros urbanos. A acidificação das precipitações de forma anormal, visto que ela pode ocorrer espontaneamente na natureza sem ser necessariamente um resultado da poluição antrópica, está associada principalmente com a liberação de $\mathrm{NO}_{\mathrm{x}}$ e $\mathrm{SO}_{2}$, em grande parte, oriundos dos processos de combustão de combustíveis fósseis. $\mathrm{Na}$ interação da energia luminosa solar com estes gases são promovidas reações com a água gasosa da atmosfera, dando origem aos ácidos que, mais tarde, presentes nas precipitações causam uma sensível diminuição de seu $\mathrm{pH}$.

O impacto das chuvas ácidas provoca profundas alterações dos ambientes naturais, das águas (acidificação de lagos e rios), dos solos e, principalmente, da vegetação, além de deteriorar muitos dos materiais empregados na construção civil e nos monumentos históricos (Ribeiro 2009).

Moreira (2007) cita que as chuvas ácidas também podem ser prejudiciais à agricultura. Chuvas com $\mathrm{pH}$ entre 2,5 e 3,0 afetam culturas tais como o alface, a beterraba, a cebola, o soja e o tabaco, causado danos (como: amarelecimento das folhas, desfolhamento prematuro, diminuição do crescimento e da produtividade). No entanto, a chuva ácida pode ter efeito positivo, a longo prazo, por causa da ação fertilizante do nitrogênio.

\subsubsection{Impacto Global}

O impacto global dos poluentes atmosféricos refere-se aqueles que podem afetar o planeta como um todo. Para Lora \& Teixeira (2001) o problema de maior importância causado pelo uso dos combustíveis fosseis é o efeito estufa, que pode ser definido como o acréscimo constante da temperatura média da Terra em conseqüência do aumento da concentração atmosférica de alguns gases, tais como o gás carbônico (CO2), os clorofluorcarbonos (CFCs), o metano (CH4), o óxido nitroso (N2O), etc. Estes gases são conhecidos como gases estufa e capturam parte da radiação infravermelha que a terra devolve para o espaço, provocando o aumento da temperatura atmosférica com as decorrentes mudanças climáticas.

O gás de efeito estufa de maior importância é o dióxido de carbono que é o principal composto resultante da combustão completa de combustíveis. Quando em grande quantidade, o gás carbônico e outros poluentes acabam formando um filtro na atmosfera, durante o dia a Terra é aquecida pelo sol e à noite perde o calor armazenado tendo, por conseqüência, uma redução de temperatura. Entretanto, com a camada de poluentes presentes, o calor fica retido na Terra, provocando um aumento na temperatura média (Moreira 2007)

O setor de transporte tem uma participação considerável nas questões climáticas. Contribuem em $22 \%$ para a emissão global de gases de efeito estufa, empregando praticamente $100 \%$ de combustíveis fósseis. (Ribeiro et al, 2000).

No Brasil $32 \%$ das emissões de carbono são originadas pelas atividades de transporte. Este número é elevado em comparação com a média mundial e se deve ao fato de que o modo rodoviário apresenta total predomínio sobre os demais. O Brasil apresenta uma das maiores taxas de crescimento das suas emissões de $\mathrm{CO} 2$ por conta da industrialização que vem ocorrendo e do crescimento das fro- 
tas de veículos existentes à combustão interna. Há, portanto, uma grande necessidade de atuação de políticas públicas eficazes neste setor, tendo em vista alterar este quadro no qual, além das alterações climáticas, há prejuízos diretos à saúde humana e ao meio ambiente (Pinto 2005).

\subsection{O SETOR DE TRANSPORTE E O USO DOS COMBUSTIVEIS DERIVADOS DO PETRÓLEO}

Segundo Loureiro (2005) a maior parte dos derivados de petróleo consumidos no mundo destina-se ao setor de transportes seguido pela indústria. Embora existam fontes alternativas com tecnologias desenvolvidas para obtenção de energia, os fatores econômicos prevalecem, uma vez que a energia gerada através da combustão de derivados de petróleo, em alguns países, ainda é mais econômica se comparada com as alternativas.

De acordo com os dados do Departamento Nacional de Trânsito (Denatran, 2011), o Brasil encerrou 2011 com uma frota de 70,5 milhões de veículos, entre automóveis, comerciais leves, caminhões, ônibus, carretas e motocicletas. Este número é 121\% maior na comparação com a frota que circulava pelo país em 2001, a qual era de aproximadamente 32 milhões de veículos.

A população brasileira, no entanto, cresceu $12 \%$ neste mesmo período. Isso significa que a relação de veículos por habitante saltou de um para cada cinco indivíduos em 2001, para pouco mais de um veículo para cada três habitantes no ano passado. Levando em conta apenas os automóveis e comerciais leves, o Brasil conta agora com um carro para cada cinco habitantes, sendo que em 2001 a relação era de um carro para cada oito habitantes (Moreira, 2012).

$\mathrm{O}$ aumento do transporte individual coincide com a expansão da capacidade instalada da indústria automobilística, fruto de uma política industrial que se pautou principalmente pela atração de novas plantas automotivas para o país. Para dar vazão a essa produção crescente, houve oferta abundante de crédito para aquisição de veículos e uma política tributária que reduziu impostos de veículos populares. Por outro lado, o aumento de renda da população, desde 2003, ampliou a base de consumidores dos veículos particulares (IPEA, 2012).

Atualmente, os combustíveis disponíveis comercialmente para aplicação automotiva no Brasil, derivados do petróleo, são o óleo diesel, a gasolina (misturada com etanol anidro). Vale ressaltar que a melhoria da qualidade dos combustíveis está sendo perseguida pelo Ministério do Meio Ambiente (MMA) por meio do Instituto Brasileiro do Meio Ambiente (IBAMA) que, em parceria com a Agência Nacional de Petróleo (ANP) e a Associação Nacional dos Fabricantes de Veículos Automotores (ANFAVEA), vem conseguindo resultados expressivos, como a retirada do chumbo da gasolina, a adição de álcool à gasolina, a redução gradativa do teor de enxofre do óleo diesel e da gasolina (Corradine, 2005).

\subsection{Gasolina}

No Brasil, a gasolina não é o derivado de maior produção, mas ainda é o combustível mais importante. O mercado consumidor é o mais representativo dentre os combustíveis. A gasolina utilizada como combustível nacional tem como característica principal a adição de etanol anidro na proporção de $25 \_1 \%$ em volume, devido à legislação vigente. A gasolina, proveniente do processo do craqueamento e refino do petróleo, é uma mistura de vários hidrocarbonetos. Essa composição determina sua qualidade; na maioria dos casos, o processo de combustão não ocorre na sua forma ideal, seja devido à composição da mistura ar-combustível, seja por ineficiência do motor ou por outro motivo qualquer. Dessa forma, a gasolina também gera como produtos dessa reação não ideal de combustão, além de água e gás carbônico, substâncias poluentes, como o monóxido de carbono (CO), os óxidos de nitrogênio (NOx), hidrocarbonetos (HC) não-queimados, material particulado, e mesmo óxidos de enxofre (SO2), devido ao enxofre presente na gasolina. Outra substância originada na combustão é o benzeno, que também é um agente cancerígeno (Loureiro 2005).

Segundo Maclean et al (2003), as principais características que definem a qualidade de uma gasolina automotiva são a volatilidade e a capacidade antidetonante, medidas, basicamente, pelos ensaios de destilação, pressão de vapor e os parâmetros de octanagem.

\subsection{2 Óleo Diesel}

O óleo diesel é um derivado de petróleo, de faixa de destilação comumente entre $220-380^{\circ} \mathrm{C}$. Este derivado é utilizado em motores automotivos de combustão interna por compressão. Devido à sua alta eficiência, durabilidade e flexibilidade, há uma tendência mundial de utilização crescente destes motores na indústria automobilística, o que reflete num aumento da demanda por diesel em relação 
aos demais derivados de petróleo. A máquina a diesel é a que alcança os maiores rendimentos (cerca de 45\%) comparada com as demais de combustão interna (Massagardi, 2004).

Chevron (2004) cita que o ciclo diesel é regulado apenas pela vazão de combustível, uma vez que a vazão de ar permanece constante com as mudanças de velocidade do motor. Como os motores a diesel geralmente operam com excesso de oxigênio, as emissões de hidrocarbonetos e de monóxido de carbono são minimizadas.

Como o diesel é composto de frações de faixas de ponto de ebulição altos (quando comparadas com gasolina), uma considerável fração do combustível carregado no cilindro está na fase liquida durante a combustão, consequentemente, a presença de diminutas gotas de combustível na câmara de combustão (altas temperaturas) conduzem a um processo de pirólise localizado do combustível, dando origem ao material particulado (MP) carbonoso. As altas temperaturas da câmara também propiciam a formação de óxidos de nitrogênio (NOx) pela reação do $\mathrm{O} 2$ com o $\mathrm{N} 2$ do ar. Existe uma temperatura critica que varia em torno de $1370^{\circ} \mathrm{C}$, dependendo da pressão, abaixo da qual os NOx não são formados em quantidades significativas. Logo, reduzindo os picos de temperatura na combustão pode-se eliminar os NOx. O óleo diesel possui uma série de padrões de especificação, sendo que os que mais afetam a emissão de poluentes são: o número de cetano, teor de enxofre, teor de aromáticos e a densidade (Loureiro 2005)

Atualmente, no Brasil, existem dois tipos de diesel: o metropolitano (tipo D) e o interior (tipo B). O primeiro é destinado ao consumo das regiões metropolitanas do país, onde é importante que o impacto ambiental da queima deste combustível seja minimizado e o segundo se destina as demais regiões (Loureiro, 2005).

\subsection{EMISSÃo de POLUENTES VEICULAR E SUAS CAUSAS.}

O trânsito de veículos é um grande colaborador nas emissões de contaminantes, principalmente nos grandes centros urbanos, onde o acúmulo de carros são mais frequentes, ou em áreas onde ainda são usados combustíveis com elevado conteúdo de enxofre. Em áreas onde a gasolina com chumbo na sua composição ainda é usada, o trânsito contribui com até $90 \%$ das concentrações totais desse metal na atmosfera, o que pode causar intoxicação, provocando uma espécie de "envenenamento do sangue".

O óxido de nitrogênio (NO) também é liberado dos motores automotivos e é considerado um gás que apresenta riscos ao meio ambiente, pois interfere no ciclo do ozônio de forma negativa, sob a ação de luz solar se transforma em NO2 e tem papel importante na formação de oxidantes fotoquímicos como o ozônio. (Tundo e Zecchini, 2007).

Os tipos mais comuns de combustíveis para utilização em transportes são gasolina para os veículos leves (automóveis) e o diesel para os veículos pesados (ônibus e caminhões). Na abordagem de Loureiro (2005), as emissões de origem veicular são resultado da combustão do combustível ou de sua evaporação.

Segundo o Plano de Controle da Poluição por Veículos em Uso - PCPV (2005) os principais poluentes lançados na atmosfera pelos veículos automotores são provenientes do processo de combustão incompleta sendo, normalmente, qualificadas e quantificadas as emissões de:

Monóxido de carbono (CO): É um gás incolor e inodoro que resulta da queima incompleta de combustíveis de origem orgânica (combustíveis fósseis, biomassa, etc...). É formada pela relação oxigênio/combustível presente na câmara de combustão e pela eficiência da queima da mistura ar/ combustível;

Hidrocarbonetos (HC): também conhecido como combustível não queimado ou, ainda, como frações de compostos orgânicos que não foram queimadas ou que sofreram apenas oxidação parcial. Diversos hidrocarbonetos como o benzeno são cancerígenos e mutagênicos, não havendo uma concentração ambiente totalmente segura.

Óxidos de nitrogênio (NOx): São formados durante processos de combustão, principalmente, pela temperatura no interior da câmara de combustão;

Dióxido de enxofre (SO2): Resulta da oxidação do enxofre, presente nos combustíveis fósseis, por ocasião da queima do combustível;

Aldeídos: Resultam da oxidação parcial do combustível durante a queima. Os principais aldeídos em termos de quantidade emitida são o formaldeído e o acetaldeído;

Material particulado (fuligem) ou partículas: Resultam da combustão das frações mais complexas de hidrocarbonetos, em condições de insuficiência de oxigênio e de tempo, para queima adequada, 
bem como de condensação de aerossóis e vapores e de desgaste ou deterioração de materiais.

Cada um desses poluentes é emitido em maior ou menor quantidade em função do combustível utilizado, do tipo de motor, da sua regulagem, da manutenção e modo de dirigir. Em veículos novos essas emissões foram bastante controladas com a adição de certas tecnologias (catalisadores, injeção eletrônica de combustível entre outros). Apesar de, individualmente, esse tipo de emissão ser aparentemente insignificante, ao se analisar o número de veículos existentes nas grandes cidades, verifica-se a geração de toneladas de poluentes por dia (Loureiro, 2005).

O uso de veículos automotores, de acordo com Mendes (2004), pode originar as emissões de gases e partículas pelo escapamento do veículo, as emissões evaporativas de combustível, as emissões de gases do cárter do motor (subprodutos da combustão que passam pelos anéis de segmento do motor e por vapores do óleo lubrificante), as emissões de partículas provenientes do desgaste de pneus, freios e embreagem, a ressuspensão de partículas de poeira do solo e as emissões evaporativas de combustível nas operações de transferência de combustível. A figura 1 mostra alguns desses pontos:

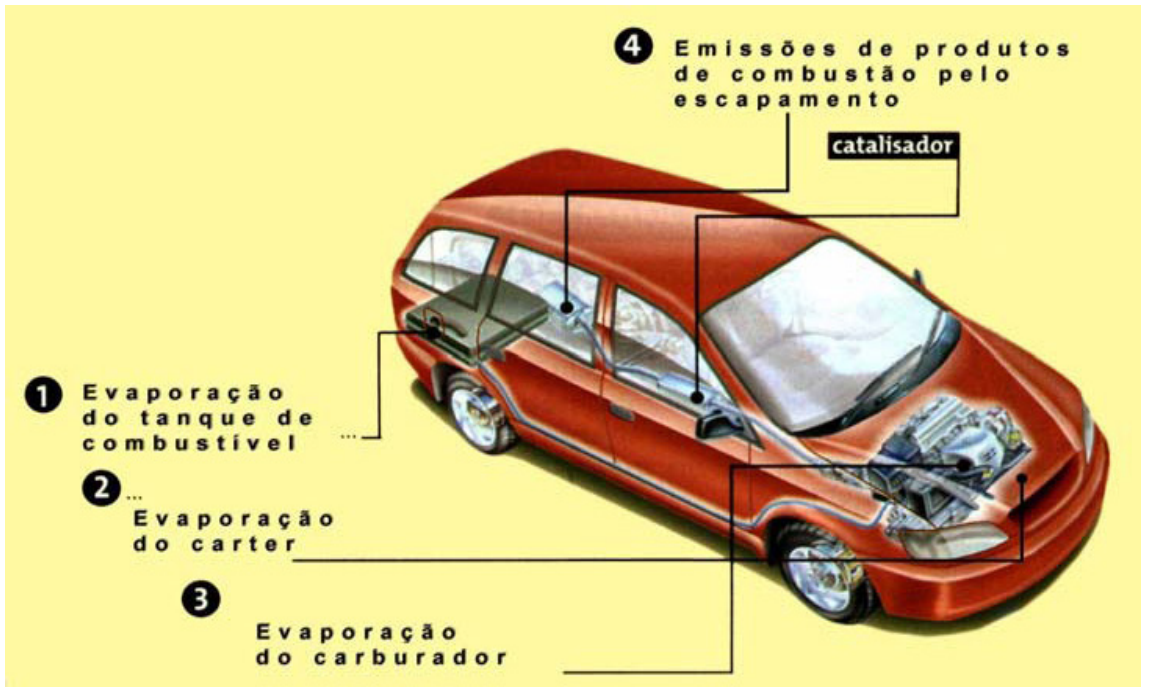

Figura 1: Pontos de emissão de poluentes do ar em veículo automotor.

Fonte: Loureiro, 2005

A emissão de gases e partículas pelo tubo de escapamento do veiculo ocorre devido às reações químicas associadas ao processo de combustão que acontecem no motor. A emissão de SOx se dá pelo teor de enxofre no combustível utilizado. Já os HC's representam, na verdade, a parcela de combustível que não foi queimada e é constituída por hidrocarbonetos, álcoois cetonas e outros compostos orgânicos (CETESB, 2002).

Os vapores de $\mathrm{HC}^{\prime}$ s emitidos através das juntas, dos respiros e pelas conexões do sistema de alimentação do combustível são chamadas de emissões evaporativas, essas emissões dependem, principalmente, da volatilidade do combustível e também das condições ambientais. As emissões de cárter são gases e vapores emitidos pelo respiro do cárter, além dos vapores de óleo lubrificante e seus produtos, ocorrem devido ao vazamento de gases de combustão e frações de combustíveis não queimados através de anéis de vedação dos pistões, durante os períodos de compressão e explosão do motor, e se caracterizam pela grande quantidade de hidrocarbonetos. Além destas emissões e também das emissões de vapores de combustível as quais ocorrem durante o abastecimento dos veículos, essa emissão é denominada como emissão de transferência (FEEMA, 2004). A tabela 1 é um exemplo de como geralmente são apresentadas as estimativas de emissões veiculares (com local de origem da emissão e tipo de combustível). 
Quadro 1 - Estimativa de Emissão das Fontes de Poluição do ar na RMSP em 2002

\begin{tabular}{|c|c|c|c|c|c|c|}
\hline \multirow{2}{*}{\multicolumn{2}{|c|}{ Fontes de Emissão (Fontes Movéis) }} & \multicolumn{5}{|c|}{ Emissão ( 1000 t/ ano) } \\
\hline & & CO & $\mathrm{HC}$ & NO & SOx & $\mathbf{M P}^{4}$ \\
\hline \multirow{5}{*}{$\begin{array}{l}\text { Tubo de } \\
\text { escapamento } \\
\text { de veículos }\end{array}$} & Gasolina $C^{1}$ & 790,2 & 84,2 & 51,8 & 9,1 & 5,2 \\
\hline & Álcool & 221,5 & 22,9 & 12,6 & $\begin{array}{ll}--- \\
\end{array}$ & --- \\
\hline & Diesel $^{2}$ & 444,4 & 72,4 & 324,5 & 11,2 & 20,2 \\
\hline & Táxi & 2,3 & 0,5 & 0,7 & 0,3 & 0,1 \\
\hline & Motocicleta e similares & 238,9 & 31,5 & 1,2 & 0,5 & 0,6 \\
\hline \multirow{3}{*}{$\begin{array}{l}\text { Carter e } \\
\text { evaporativa }\end{array}$} & Gasolina C & --- & 134,1 & --- & --- & --- \\
\hline & Álcool & --- & 17,2 & --- & --- & --- \\
\hline & $\begin{array}{l}\text { Motocicletas e } \\
\text { similares }\end{array}$ & --- & 17,0 & --- & --- & --- \\
\hline Pneus $^{3}$ & Todos os tipos & --- & --- & --- & --- & 8,3 \\
\hline \multirow{2}{*}{$\begin{array}{l}\text { Operações de } \\
\text { transferência de } \\
\text { combustível }\end{array}$} & Gasolina C & --- & 12,4 & --- & --- & --- \\
\hline & Álcool & --- & 0,6 & --- & --- & --- \\
\hline
\end{tabular}

Gasolina contendo $22 \%$ de etanol anidro e 700 ppm de enxofre (massa)

Diesel: tipo metropolitano com 1100 ppm de enxofre ( massa)

Emissão composta para o ar (partículas) e para o solo (impregnação)

MP refere-se ao total de material particulado, sendo que as partículas inaláveis são uma fração deste total

Fonte: CETESB, 2002.

\subsection{LEGISLAÇÃO BRASILEIRA REFERENTE A EMISSÕES VEICULARES}

Loureiro (2005) cita que, dentre os países da America do Sul, o primeiro a ter uma legislação voltada para reduções de emissões provenientes de veículos foi o Brasil. Hoje a legislação brasileira já conta com amplo amparo legal para medidas de controle referentes à poluição veicular

Segundo Azeredo e Rodrigues (2003) o Brasil, desde o final da década de 80, sofreu grandes avanços referentes ao controle das emissões de gases poluentes e partículas provenientes de veículos automotores, isso, devido principalmente ao Programa de Controle de Poluição do Ar por Veículos Automotores (PROCONVE), instituído pelo Conselho Nacional do Meio Ambiente (CONAMA) que estabeleceu um cronograma de redução gradativa da emissão de poluentes para veículos automotores tanto leves quanto pesados. O PROCONVE deu prioridade ao segmento de veículos leves devido ao crescente número destes e sua utilização intensiva (INEA, 2007).

Além do PROCONVE, existe uma vasta quantidade leis e resoluções tanto a nível municipal como estadual e federal, referentes à redução nas emissões de gases poluentes por veículos das quais algumas são citadas abaixo:

Resolução CONMETRO n 01, de 23 de outubro de 1987 - Institui em caráter Nacional o Programa Nacional de Certificação de Conformidade de Veículos Automotores Emissões PROVEM

Resolução CONAMA n ${ }^{\circ}$ 003/90 de 28.06.1990- Estabelece os padrões de qualidade do ar e ainda os critérios para episódios críticos de poluição atmosférica. 
Resolução CONAMA n 07, de 31 de agosto de 1993 - Define as diretrizes básicas e padrões de emissão para o estabelecimento de programas de inspeção e manutenção de veículos ciclo Otto em uso I/M;

Resolução CONAMA n 08, de 31 de agosto 1993. Define as diretrizes básicas para o estabelecimento de programas de Inspeção e Manutenção de Veículos ciclo Diesel,

Resolução CONAMA n. ${ }^{\circ 297 / 02}$ de 26.02.2002- Institui o Programa de Controle da Poluição do Ar por Motocicletas e Veículos Similares - PROMOT, e estabelece os limites de emissões para os ciclomotores, motociclos e similares novos.

\subsection{PADRÃO DA QUALIDADE DO AR}

Um padrão de qualidade do ar define um limite máximo para concentração de um componente atmosférico, esses padrões são baseados em estudos científicos verificando os efeitos produzidos por poluentes específicos e são fixados em níveis que possam propiciar uma margem de segurança adequada, esses limites são importantes, pois garantem a proteção da saúde e do bem estar das pessoas. (Lisboa e Kawano, 2007).

Segundo Loureiro (2005) os padrões de qualidade do ar segundo a Resolução CONAMA n ${ }^{\circ} 003$ de 28/06/90 são definidos pelos seguintes parâmetros de poluentes atmosféricos: dióxido de enxofre, partículas totais em suspensão, partículas inaláveis, fumaça, monóxido de carbono, ozônio e dióxido de nitrogênio . Carvalho (2009) comenta que tais padrões possuem uma dupla função, pois revelam tanto um diagnóstico da qualidade do ar atmosférico, quanto possibilitam a responsabilização dos causadores da poluição.

Segundo o PCPV (2011) são estabelecidos dois tipos de padrões de qualidade do ar: os padrões primários e secundários. São padrões primários de qualidade do ar: as concentrações de poluentes que, ultrapassadas, poderão afetar a saúde da população, podendo ser entendidos como níveis máximos toleráveis de concentração de poluentes atmosféricos. Consideram-se padrões secundários de qualidade do ar: as concentrações de poluentes atmosféricos abaixo dos quais se prevê o mínimo efetivo adverso sobre o bem estar da população, assim como o mínimo dano à flora e à fauna, aos materiais e ao meio ambiente em geral, podendo ser entendidos como níveis desejáveis de concentração de poluentes, constituindo-se em meta a ser alcançada em longo prazo. Os padrões de qualidade do ar são apresentados na Tabela 2.

\begin{tabular}{|c|c|c|c|c|}
\hline Poluentes & $\begin{array}{l}\text { Tempo de } \\
\text { Amostra }\end{array}$ & $\begin{array}{l}\text { Padrão } \\
\text { Primário } \\
\end{array}$ & $\begin{array}{l}\text { Padrão Secundário } \\
\mu \mathrm{m} / \mathrm{m}^{3}\end{array}$ & Metódo de Medição \\
\hline PTs & $24 \mathrm{~h}(1)$ & $\begin{array}{l}240 \\
80\end{array}$ & $\begin{array}{l}150 \\
60\end{array}$ & $\begin{array}{l}\text { Amostrador de } \\
\text { grandes volumes }\end{array}$ \\
\hline $\mathrm{SO}_{2}$ & MGA (2) & $\begin{array}{l}365 \\
80\end{array}$ & $\begin{array}{l}100 \\
40\end{array}$ & Pararosanilina \\
\hline $\mathrm{CO}$ & $\begin{array}{l}1 \mathrm{~h}(1) \\
8 \mathrm{~h}(2)\end{array}$ & $\begin{array}{l}40.000 \\
(35 \mathrm{ppm}) \\
10.000 \\
\text { (9ppm) }\end{array}$ & $\begin{array}{l}40.000 \\
(35 \mathrm{ppm}) \\
10.000 \\
(9 \mathrm{ppm})\end{array}$ & $\begin{array}{l}\text { Infra-vermelho não } \\
\text { dispertivo }\end{array}$ \\
\hline $\mathrm{O}_{3}$ & 1h (1) & 160 & 160 & Quimioluminescência \\
\hline Fumaça & $\begin{array}{l}24 \mathrm{~h}(1) \\
\operatorname{MAA}(3)\end{array}$ & $\begin{array}{l}150 \\
50\end{array}$ & $\begin{array}{l}100 \\
40\end{array}$ & Refletância \\
\hline $\begin{array}{l}\text { Particulas } \\
\text { Inaláveis }\end{array}$ & $\begin{array}{l}\text { 24h (1) } \\
\text { MAA (3) }\end{array}$ & $\begin{array}{l}150 \\
50\end{array}$ & $\begin{array}{l}150 \\
50\end{array}$ & $\begin{array}{l}\text { Separação } \\
\text { Inercial/filtração }\end{array}$ \\
\hline $\mathrm{NO}_{2}$ & $\begin{array}{l}1 \mathrm{~h}(1) \\
\text { MAA (3) }\end{array}$ & $\begin{array}{l}320 \\
100 \\
\end{array}$ & $\begin{array}{l}190 \\
100 \\
\end{array}$ & Quimioluminescência \\
\hline
\end{tabular}

Tabela2: Padrões de qualidade do ar

Fonte: Plano de Controle da Poluição por Veículos em Uso- PCPV, 2005 


\section{CONSIDERAÇÕES FINAIS}

É possível perceber que diversos fenômenos nocivos ao meio ambiente (chuva ácida, efeito smog, efeito estufa) e também ao homem (doenças respiratórias, alergias e outros) estão associados a este tipo de poluição. O governo estabeleceu diversas medidas para que o nível de poluentes emitidos por veículos estivesse dentro de um nível considerado aceitável, a meta mais importante a ser concluída é que a melhoria da qualidade do ar que respiramos não depende apenas de uma instituição e, sim, de uma ação conjunta de diversos órgãos e atividades que podemos citar: melhoria da qualidade dos laboratórios de teste das montadoras e das entidades ambientais governamentais (para efeito de fiscalização), do desenvolvimento de tecnologia dos motores e equipamentos; melhoria do combustível e até mesmo dos urbanistas e engenheiros de trânsito, que deverão evitar a concentração de veículos em corredores de tráfego; por isso, estudos futuros são necessários para aprimorar as medidas para redução da poluição atmosférica de origem veicular.

\section{REFERÊNCIAS}

AZEREDO, R. N.; RODRIGUES, R. A. Atuação da Metrologia Legal no Controle da Poluição do Ar por Veículos Automotores. Instituto Nacional de Metrologia, Normalização e Qualidade Industrial - INMETRO. Diretoria de Metrologia Legal - DIMEL. Divisão de Metrologia na Saúde, Segurança e Meio Ambiente DISMA. Rio de Janeiro, RJ, Brasil, 2003

AZUAGA. Danos ambientais causados por veículos leves no Brasil. Tese de mestrado em Engenharia - UFRJ, 2000.

BRAGA, et al., Introdução a Engenharia Ambiental, 2ed, Prentice Hall Brasil, 2005 .

Disponível em : <http://conhecimentovaleouro.blogspot.com.br/2011/07/introducao-engenharia-ambiental-2.html> Acesso em: 11 fev. 2013

CARVAlHO M. B. F. Poluição Atmosférica E Mudanças Climáticas. 2009. Disponível em: <http://www. puc-rio.br/pibic/relatorio_resumo2009/relatorio/dir/mariana_carvalho.pdf>

Acesso em: 11-02-2013

CETESB. Relatório de Qualidade do Ar no Estado de São Paulo. 2002. Companhia de Tecnologia de Saneamento Ambiental. São Paulo, SP.

CETESB. Relatório Anual de Qualidade do Ar no Estado de São Paulo. 2004. Companhia de Tecnologia de Saneamento Ambiental. São Paulo, SP.

CETESB. Qualidade do Ar no Estado de São Paulo. 2011. Governo do Estado de São Paulo - Secretaria do Meio Ambiente, Companhia Ambiental do Estado de São Paulo. São Paulo, SP.

CHEVRON; Diesel Fuel and Air Quality,2004. Disponível em: www.chevron.com/prodserv/fuels Acesso em : 12 fev. 2013

CORRADINE. Efeito Da Temperatura Do Líquido de Arrefecimento na Produção de Emissões Poluentes De Motor De Ignição Por Faísca. Trabalho de Conclusão de Curso apresentado à Escola Politécnica da Universidade de São Paulo- 2005.

CUNHA, R. M.P. Estudo do Transporte de Poluentes na Região do Pólo Petroquímico, Localizado Em Triúnfo- Rs. 2002. Disponível em <www.lume.ufrgs.br/bitstream/handle/10183/6325/000528464. 
pdf?sequence $=1>$ Acesso em: 11 jan. 2013

DENATRAN, Frota 2011 Disponível em:< www.denatran.gov.br/frota.htm> Acesso em: 14 jan. 2013

FEEMA, 2004: Inventário de Fontes Emissoras de Poluentes Atmosféricos da Região Metropolitana do Rio de Janeiro. Disponível em:< www.feema.rj.gov.br> Acesso em: 15 jan. 2013

FIZIOLA, I.M.; YAMASHITA, Y.; VERAS, C.A.G. 2004. Nível de emissão de gases de veículos automotores leves do ciclo otto: valores referenciais. Mestrado em Transportes Universidade de Brasília.

GUIMARÃES Estudo Sobre As Relações Entre As Doenças Respiratórias E A Poluição Atmosférica E Variáveis Climáticas, Na Cidade De Curitiba, Paraná, Brasil. Tese apresentada ao Curso de Pós graduação em Engenharia Florestal, UFP- CURITIBA 2011.

INSTITUTO ESTADUAL DO AMBIENTE - INEA. 2007. Programa de Inspeção/Manutenção de Veículos. Disponível em:< http://www.inea.rj.gov.br/fma/proconve-promot.asp.> Acesso em: 04 Jan. 2013.

IPEIA, 2011. Poluição Veicular Atmosférica. No 313 Disponível em: <www.cnt.org.br/Imagens\%20CNT/.../ comunicado_ipea220911.pdf> Acesso em 17 jan. 2013

LISBOA H. M. e KAWANO M. Controle da Poluição atmosférica. Cap. IV monitoramento de poluentes Atmosféricos. dez 2007. Disponível em: <http://www.lcqar.ufsc.br/adm/aula/Cap\%204\%20Monitoramento\%20da\%20QUALIDADE\%20DO\%20AR.pdf> Acesso em: 11 jan. 2013

LORA, E.S; TEIXEIRA, F.N. Energia e meio ambiente. Conservação de energia: eficiência energética de instalações e equipamentos. Itajubá, MG: FUPA, 2001, cap. 2, p.30-89.

LOUREIRO L. N.; Panorâmica Sobre Emissões Atmosféricas Estudo De Caso: Avaliação Do Inventário Emissões Atmosféricas da Região Metropolitana Do Rio De Janeiro Para Fontes Móveis. Tese Universidade federal do Rio de Janeiro, 2005.

MASSAGARDI, M. Diesel - Oportunidades e Desafios. In: Hart World Fuels Conference Latin American \& the Caribbean. Rio de Janeiro, 2004

MENDES. Avaliação de programas de controle de poluição atmosférica por veículos leves no Brasil. Tese (Doutorado) - Universidade Federal do Rio de Janeiro 2004.

MIRANDA E BAPTISTA. A Poluição Do Ar Na Cidade de Goiânia-Go e a Prática de Exercícios Físicos. 2008 -EFR Vol. 2, No 3.

MOREIRA O. C. L.; Comparação Entre Os Poluentes Atmosféricos E Ruídos Emitidos Por Uma Caldeira Flamotubular Movida A Gás Natural E A Óleo Combustível Bpf 2a. Dissertação Universidade Federal do Mato Grosso de Sul, 2007.

MOREIRA T.; Trânsito intenso das grandes cidades reflete na qualidade de vida da população. 2005. Disponível: <http://motordream.uol.com.br/noticias/ver/2012/03/02/frota-brasileira-de-veiculos-mais-que-dobrou-nos-ultimos-10-anos> Acesso em: 11 jan. 2013

MOTA, S. Impactos ambientais das atividades humanas. Introdução à engenharia ambiental. 2.ed. Rio de Janeiro: ABES, 2000.

PINTO. Análise das emissões veiculares em regiões urbanase metodologia para quantificação de poluentes. Dissertação Universidade do Estado do Rio de Janeiro- UERJ, 2005. 
PCPV (2005) Plano de Controle da Poluição por Veículos em Uso. Governo Do Estado Do Ceará.

Disponível em:< http://www.semace.ce.gov.br/wp-content/uploads/2011/08/GOVERNO-DO-ESTADO-DO-CEAR\%C3\%81-PCPV-01.pdf> Acesso em: 14 jan. 2013.

RIBEIRO. Impactos da chuva acida nas florestas. 2009. Disponível em $:<$ http://www.ebah.com.br/content/ ABAAAAO5cAK/impactos-chuva-acida-nas-florestas > Acesso em: 15 jan. 2013

RIBEIRO, S. K., COSTA, C. V., David, E.G., Real, M. V., D'Agosto, M. A. Transporte mudanças climáticas. Rio de Janeiro, MAUAD Editora Ltda. 2000

TEIXEIRA, E. C; FELTES, S; SANTANA, E. R. R. Estudo Das Emissões De Fontes Móveis Na Região Metropolitana De Porto Alegre, Rio Grande Do Sul. Química Nova, Vol. 31, pag 244, 2008.

TUNDO P. e ZECCHINI F. Mudanças climáticas globais . Publicado em Julho de 2007 pelo Consórcio Inter-Universitário Nacional "A Química para o Ambiente" e IUPAC União Internacional de Química Pura e Aplicada Disponível em: <http://www.incaweb.org/publications/pdf/climate_monograph_por.pdf $>$ Acesso em: 11 fev. 2013

VESILIND, P. A.; MORGAN, S. M. Introdução à Engenharia Ambiental. São Paulo: Cengage Learning, $2^{\circ}$ ed, 2011. 